\title{
Diagnostic Investigations of Gastroesophageal Reflux Disease: Who and When to Refer and for What Test?
}

\author{
Arne Kandulski Lukas Moleda Martina Müller-Schilling \\ Department of Internal Medicine I, University Hospital Regensburg, Regensburg, Germany
}

Keywords

Gastroesophageal reflux disease - pH-metry .

Diagnostics · Therapy · Proton pump inhibitors

\section{Summary}

Background: Due to the high prevalence and incidence of patients with gastroesophageal reflux disease (GERD), the diagnostic workup of patients with symptoms of GERD needs to be balanced between empiric antisecretory therapy and further functional assessment including endoscopy and reflux monitoring. Methods: This article is based on a literature review (PubMed, Medline) using the terms 'gastroesophageal reflux disease' or 'GERD' and 'diagnosis', 'therapy', or 'PPI' with special and critical analysis of the current 'Porto' consensus report. Results and Conclusions: Further diagnostics are mandatory in case of alarm symptoms as well as atypical or persistent symptoms under adequate therapy with proton pump inhibitors (PPI). In general, the clinical situation needs to be clarified before sending the patients for reflux monitoring. The question is not only when and whom to test but also how to test: on or off PPI therapy, $\mathrm{pH}$-metry, or combined $\mathrm{pH}$-impedance analysis. These questions have been defined in a recent consensus report of an international panel of experts and are further discussed in this article.

(c) 2018 S. Karger GmbH, Freiburg

\section{Introduction}

Gastroesophageal reflux disease (GERD) is one of the most common diseases in developed Western world countries. Up to $20 \%$ of the US population suffer from weekly symptoms, and even up to $40 \%$ report about intermittent symptoms $[1,2]$.

It is evident that GERD is caused by gastric contents exposed to the distal esophagus, causing troublesome symptoms and/or mucosal lesions [3]. The severity of symptoms is independent from the presence or severity of mucosal lesions $[4,5]$. All patients, notwithstanding if they present with erosive reflux disease (ERD) or with normal appearing gastroesophageal junction (non-erosive reflux disease (NERD)), show distinct changes of the mucosa, such as molecular and microscopic signs of inflammation $[6,7]$.

In the presence of heartburn and regurgitation, clinical guidelines recommend GERD to be diagnosed as a symptomatic disease and to start antisecretory treatment with proton pump inhibitors (PPI) $[8,9]$. Regarding the amount of patients, this is also a pragmatic way of disease management and to prevent an overload of healthcare systems. In the presence of alarm symptoms (dysphagia, anemia, bleeding, weight loss) and atypical symptoms (chest pain, laryngopharyngeal symptoms), upper endoscopy is mandatory (esophagogastroduodenoscopy (EGD)) [10, 11].

In case of persisting symptoms, exclusion of esophageal lesions during EGD, uncertainties in the proper diagnosis of GERD, or persisting symptoms on PPI therapy despite endoscopic diagnosis of ERD, esophageal physiological tests are recommended [12, 13]. Diagnostic criteria and cutoff values for esophageal reflux monitoring have been published previously $[11,14,15]$.

In daily practice, there are still some uncertainties when to send patients for reflux monitoring or upper endoscopy, i.e. on PPI treatment or after having stopped a previously started antisecretory medication. Therefore, an international consensus group of experts

\section{KARGER

(c) 2018 S. Karger GmbH, Freiburg
PD Dr. med. Arne Kandulski 
Fig. 1. Clinical spectrum of GERD phenotypes defined by endoscopy and esophageal reflux monitoring (modified from [21]).

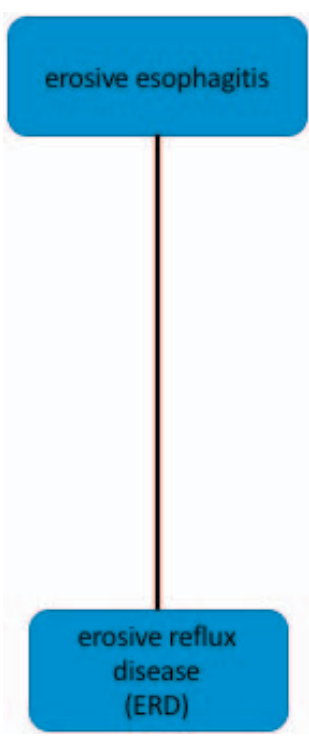

in the field updated the recommendations regarding indications, interpretation, diagnosis, and classification of GERD subtypes [16, 17]. One of the most important advances in clinical decision making and management is the differentiation of patients with unproven GERD and proven GERD in patients with endoscopic or physiological evidence of GERD, which directs esophageal reflux monitoring on or off PPI therapy.

Within this article, we discuss the major issues and aims as well as recommendations for daily clinical practice that are delineated in this updated consensus of dedicated experts.

\section{GERD Phenotypes}

Traditionally, GERD phenotypes are endoscopically defined as ERD in the presence of esophageal lesions and NERD in case of endoscopically normal appearing mucosa of the distal esophagus. The presence of normal appearing esophageal mucosa in up to $70 \%$ of the patients with GERD symptoms (included under the umbrella term of 'NERD') documents the high specificity but low sensitivity of endoscopy for GERD diagnosis $[18,19]$. In case of a normal appearing gastroesophageal junction, ambulatory reflux monitoring is mandatory to detect pathological esophageal exposure to gastric contents and association of symptoms with reflux episodes (symptom association probability (SAP) > 95\% and symptom index $(\mathrm{SI})>50 \%)[19,20]$. According to the Rome IV criteria, GERD phenotypes are characterized in patients with:

(1) ERD when having erosive esophagitis,

(2) 'true' NERD documented by means of pathological acid exposure time in ambulatory $\mathrm{pH}$ monitoring,

(3) patients with esophageal hypersensitivity (normal acid exposure but positive symptom association), and

(4) patients with functional heartburn other differential diagnosis (normal acid exposure and no symptom association) (fig. 1) $[21,22]$.

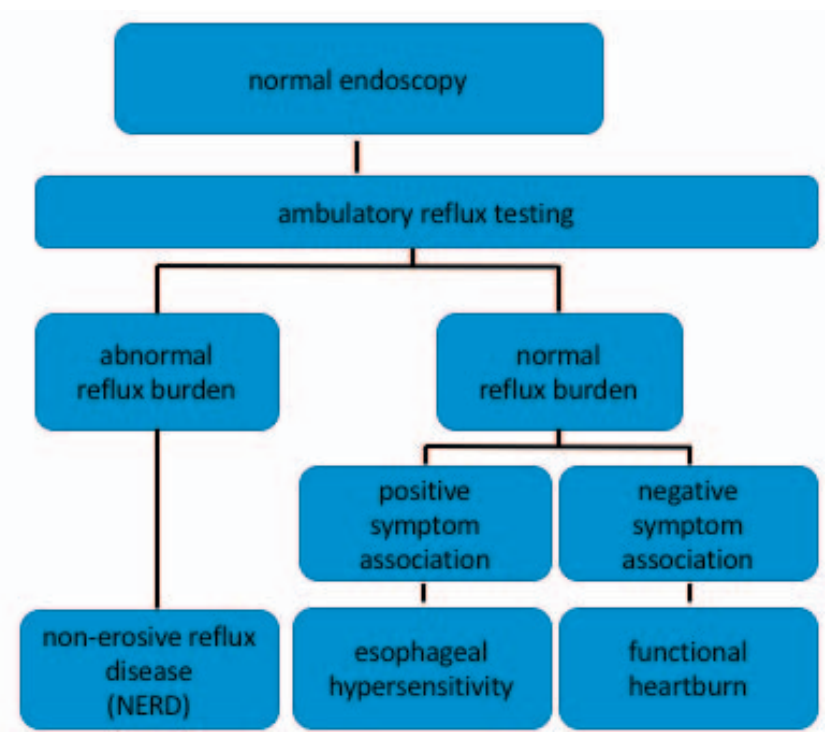

\section{Definition of Distinct Clinical Settings of Unproven} and Proven GERD

Due to the high prevalence of typical GERD symptoms in Western world communities [1, 2], patients suffering from typical symptoms are initially managed empirically with PPI. Responsiveness to empiric PPI therapy in this clinical situation of unproven GERD predicts a high likelihood that these patients suffer from symptomatic GERD. Though a sensitivity of around $80 \%$ can be stated, the specificity of the so-called 'PPI test' to predict mucosal lesions of erosive esophagitis or an abnormal acid exposure in physiological reflux testing is low $(50-60 \%)[23,24]$.

Atypical symptoms, persisting symptoms despite adequate PPI therapy, or the presence of alarm symptoms demand further diagnostic steps starting with EGD, with biopsies to rule out other diseases, such as eosinophilic or infectious esophagitis or other mucosal processes. Persisting symptoms as well as atypical symptoms also necessitate ambulatory reflux monitoring to confirm or exclude the proper diagnosis of GERD.

Summarizing most clinical scenarios, ambulatory reflux monitoring has finally to rule out or confirm abnormal reflux burden to the distal esophagus [25]. The question to be answered by the clinician is when and how to perform reflux monitoring (on or off PPI; $\mathrm{pH}$-metry or $\mathrm{pH}$-impedance), and finally led to the concept of unproven and proven GERD in the consensus statement [16].

Unproven GERD is thereby defined as the absence of prior evidence of GERD, i.e. no prior endoscopic evidence (erosive esophagitis > Los Angeles classification grade B; stricture; Barrett's esophagus) and no prior abnormal ambulatory reflux monitoring. The question to be answered is if the patient is properly diagnosed as suffering from GERD. Esophageal reflux testing in these patients should be performed off PPI therapy. Similarly, evidence of GERD needs to be proven before antireflux surgery. Surgical guidelines recommend to stop a current PPI therapy at least 7-10 days prior to testing [26]. 
Fig. 2. Clinical scenarios and diagnostic algorithm in case of GERD symptoms according to the updated Porto consensus statement (modified from [17]).

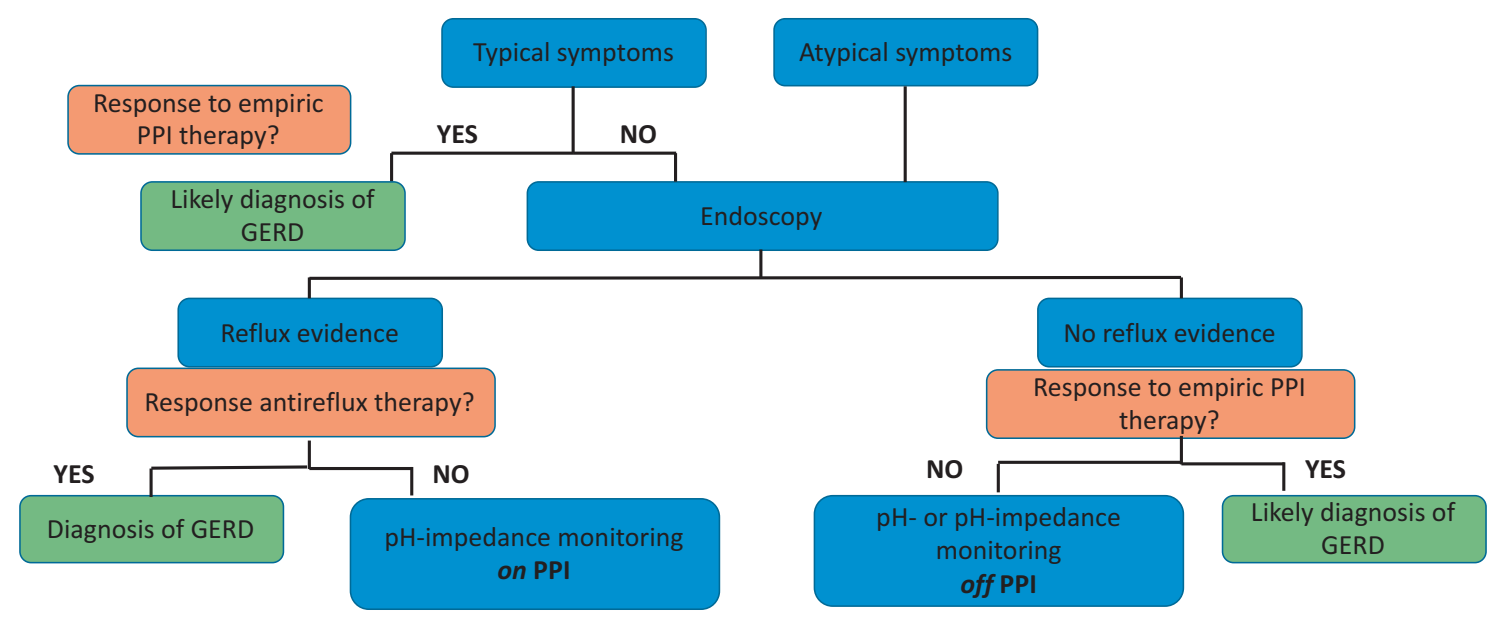

Repeated or prolonged wireless $\mathrm{pH}$-metry can be considered in case of a strong clinical suspicion and a previous negative reflux testing because of a day-to-day variability of reflux testing, and prolonged analysis can further increase the diagnostic yield [15, 27].

In contrast, proven GERD is defined by prior endoscopic evidence of GERD or a prior abnormal reflux testing. The objective answered by ambulatory reflux monitoring in these patients is to determine if persisting symptoms can be linked to ongoing reflux episodes under PPI therapy; mainly weekly acidic reflux episodes are supposed to induce symptoms $[28,29]$. In this clinical scenario, classic $\mathrm{pH}$-metry is not sufficient to answer this question, and $\mathrm{pH}$ impedance on PPI therapy should be performed.

Figure 2 summarizes the clinical scenarios and diagnostic algorithm in case of GERD symptoms with regard to proven GERD and unproven GERD and monitoring on or off PPI therapy.

\section{Mucosal Changes and Additional Impedance Metrics in the Differential Diagnosis of GERD}

Esophageal mucosal changes such as dilated intercellular spaces, basal cell hyperplasia, and papillary elongation have been described in patients with GERD and have been linked to a reduced transepithelial resistance and higher epithelial permeability [30, 31]. Esophageal biopsies evaluating these changes in patients with suspected GERD have demonstrated moderate to good sensitivity and specificity [32]. By calculating a global score of these distinct changes, the definition of 'microscopic esophagitis' has been used to distinguish patients with NERD from patients with functional heartburn as well as healthy controls with good accuracy $[6,7]$. Conversely, there are some restrictions, mainly because of low specificity of these morphological changes and variations of intraand interobserver agreement between pathologists, which limit the use of histopathological assessment of GERD in clinical practice $[33,34]$. Mean baseline mucosal impedance signals, especially when measured during nighttime without swallow-associated artefacts, are inversely correlated with esophageal acid exposure and morphological changes, such as dilated intercellular spaces. Low baseline impedance values are supposed to correlate with impaired mucosal integrity and transepithelial permeability $[35,36]$. Lower baseline impedance values $(<2,200 \Omega)$ have been found in patients with proven GERD (ERD and NERD) and have been demonstrated to distinguish from patients with functional heartburn [37-39]. Therefore, analysis of mean baseline impedance values is discussed as a complementary tool during $\mathrm{pH}$-impedance monitoring.

\section{Conclusion}

Evidence from clinical studies and modern tools in the diagnostic workup of GERD have specified the clinical spectrum and phenotypes of GERD. Diagnostic algorithms have been proposed in a consensus statement of leading experts in the field. Different clinical scenarios have been defined for the use of various reflux monitoring modalities ( $\mathrm{pH}$-metry, $\mathrm{pH}$-impedance), distinct cutoffs of the metrics have been stated, and a clear statement has been made when to perform reflux monitoring on or off PPI therapy.

\section{Disclosure Statement}

None of the authors has financial or other relations to declare.

\section{References}

1 El-Serag HB, Sweet S, Winchester CC, Dent J: Update on the epidemiology of gastro-oesophageal reflux disease: a systematic review. Gut 2014;63:871-880.

2 Boeckxstaens G, El-Serag HB, Smout AJPM, Kahrilas PJ: Symptomatic reflux disease: the present, the past and the future. Gut 2014;63:1185-1193.
3 Vakil N, van Zanten SV, Kahrilas P, et al: The Montreal definition and classification of gastroesophageal reflux disease: a global evidence-based consensus. Am J Gastroenterol 2006;101:1900-1920.
4 Kandulski A, Peitz U, Mönkemüller K, Neumann H, Weigt J, Malfertheiner P: GERD assessment including $\mathrm{pH}$ metry predicts a high response rate to PPI standard therapy. BMC Gastroenterol 2013;13:12. 
5 Kulig M, Nocon M, Vieth M, et al: Risk factors of gastroesophageal reflux disease: methodology and first epidemiological results of the ProGERD study. J Clin Epidemiol 2004;57:580-589.

6 Kandulski A, Jechorek D, Caro C, et al: Histomorphological differentiation of non-erosive reflux disease and functional heartburn in patients with PPI-refractory heartburn. Aliment Pharmacol Ther 2013;38:643-651.

7 Savarino E, Zentilin P, Mastracci L, et al: Microscopic esophagitis distinguishes patients with non-erosive reflux disease from those with functional heartburn. J Gastroenterol 2013;48:473-482.

8 Dellon ES, Gonsalves N, Hirano I, Furuta GT, Liacouras C, Katzka D: ACG clinical guideline: evidenced based approach to the diagnosis and management of esophageal eosinophilia and eosinophilic esophagitis (EoE). Am J Gastroenterol 2013;108:679-692; quiz 693.

9 Kahrilas PJ, Smout AJPM: Esophageal disorders. Am J Gastroenterol 2010;105:747-756.

10 Muthusamy VR, Lightdale JR, Acosta RD, et al: The role of endoscopy in the management of GERD. Gastrointest Endosc 2015;81:1305-1310.

11 Kahrilas PJ, Shaheen NJ, Vaezi MF: American Gastroenterological Association Institute technical review on the management of gastroesophageal reflux disease. Gastroenterology 2008;135:1392-1413.

12 Pandolfino JE: Esophageal function testing. Gastrointest Endosc Clin N Am 2014;24:xiii-xiv.

13 Pandolfino JE, Vela MF: Esophageal-reflux monitoring. Gastrointest Endosc 2009;69:917-930.e1.

14 Sifrim D, Castell D, Dent J, Kahrilas PJ: Gastrooesophageal reflux monitoring: review and consensus report on detection and definitions of acid, non-acid, and gas reflux. Gut 2004;53:1024-1031.

15 Pandolfino JE, Richter JE, Ours T, Guardino JM, Chapman J, Kahrilas PJ: Ambulatory esophageal pH monitoring using a wireless system. Am J Gastroenterol 2003;98:740-749.

16 Roman S, Gyawali CP, Savarino E, et al: Ambulatory reflux monitoring for diagnosis of gastro-esophageal reflux disease: update of the Porto consensus and recommendations from an international consensus group. Neurogastroenterol Motil 2017;29:1-15.

17 Savarino E, Bredenoord AJ, Fox M, Pandolfino JE, Roman S, Prakash Gyawali C: Expert consensus document: advances in the physiological assessment and diagnosis of GERD. Nat Rev Gastroenterol Hepatol 2017;14:665-676.

18 Fass R: Erosive esophagitis and nonerosive reflux disease (NERD): comparison of epidemiologic, physiologic, and therapeutic characteristics. J Clin Gastroenterol 2007;41:131-137.
19 Savarino E, Zentilin P, Savarino V: NERD: an umbrella term including heterogeneous subpopulations. Nat Rev Gastroenterol Hepatol 2013;10:371-380.

20 Bredenoord AJ, Weusten BLAM, Smout AJPM: Symptom association analysis in ambulatory gastro-oesophageal reflux monitoring. Gut 2005;54:1810-1817.

21 Aziz Q, Fass R, Gyawali CP, Miwa H, Pandolfino JE, Zerbib F: Esophageal disorders. Gastroenterology 2016;150:1368-1379.

22 Nikaki K, Woodland P, Sifrim D: Adult and paediatric GERD: diagnosis, phenotypes and avoidance of excess treatments. Nat Rev Gastroenterol Hepatol 2016;13: 529-542.

23 Fass R, Ofman JJ, Gralnek IM, et al: Clinical and economic assessment of the omeprazole test in patients with symptoms suggestive of gastroesophageal reflux disease. Arch Intern Med 1999;159:2161-2168.

24 Fass R, Ofman JJ, Sampliner RE, Camargo L, Wendel $\mathrm{C}$, Fennerty MB: The omeprazole test is as sensitive as 24-h oesophageal $\mathrm{pH}$ monitoring in diagnosing gastrooesophageal reflux disease in symptomatic patients with erosive oesophagitis. Aliment Pharmacol Ther 2000;14:389-396.

25 Richter JE, Pandolfino JE, Vela MF, et al: Utilization of wireless $\mathrm{pH}$ monitoring technologies: a summary of the proceedings from the Esophageal Diagnostic Working Group. Dis Esophagus 2013;26:755-765.

26 Jobe BA, Richter JE, Hoppo T, et al: Preoperative diagnostic workup before antireflux surgery: an evidence and experience-based consensus of the esophageal diagnostic advisory panel. J Am Coll Surg 2013;217: 586-597.

27 Penagini R, Sweis R, Mauro A, Domingues G, Vales A, Sifrim D: Inconsistency in the diagnosis of functional heartburn: usefulness of prolonged wireless ph monitoring in patients with proton pump inhibitor refractory gastroesophageal reflux disease. J Neurogastroenterol Motil 2015;21:265-272.

28 Mainie I, Tutuian R, Shay S, et al: Acid and non-acid reflux in patients with persistent symptoms despite acid suppressive therapy: a multicentre study using combined ambulatory impedance-pH monitoring. Gut 2006;55:1398-1402

29 Zerbib F, Roman S, Ropert A, et al: Esophageal pHimpedance monitoring and symptom analysis in GERD: a study in patients off and on therapy. Am J Gastroenterol 2006;101:1956-1963.
30 Van Malenstein H, Farré R, Sifrim D: Esophageal dilated intercellular spaces (DIS) and nonerosive reflux disease. Am J Gastroenterol 2008;103:1021-1028.

31 Farré R, van Malenstein H, De Vos R, et al: Short exposure of oesophageal mucosa to bile acids, both in acidic and weakly acidic conditions, can impair mucosal integrity and provoke dilated intercellular spaces. Gut 2008;57:1366-1374.

32 Zentilin P, Savarino V, Mastracci L, et al: Reassessment of the diagnostic value of histology in patients with GERD, using multiple biopsy sites and an appropriate control group. Am J Gastroenterol 2005;100:22992306

33 Yerian L, Fiocca R, Mastracci L, et al: Refinement and reproducibility of histologic criteria for the assessment of microscopic lesions in patients with gastroesophageal reflux disease: the Esohisto Project. Dig Dis Sci 2011;56:2656-2665.

34 Fiocca R, Mastracci L, Riddell R, et al: Development of consensus guidelines for the histologic recognition of microscopic esophagitis in patients with gastroesophageal reflux disease: the Esohisto project. Hum Pathol 2010;41:223-231.

35 Patel A, Wang D, Sainani N, Sayuk GS, Gyawali CP Distal mean nocturnal baseline impedance on $\mathrm{pH}$-impedance monitoring predicts reflux burden and symptomatic outcome in gastro-oesophageal reflux disease. Aliment Pharmacol Ther 2016;44:890-898.

36 Frazzoni M, Savarino E, de Bortoli N, et al: Analyses of the post-reflux swallow-induced peristaltic wave index and nocturnal baseline impedance parameters increase the diagnostic yield of impedance-pH monitoring of patients with reflux disease. Clin Gastroenterol Hepatol 2016;14:40-46.

37 Kessing BF, Bredenoord AJ, Weijenborg PW, Hemmink GJM, Loots CM, Smout AJPM: Esophageal acid exposure decreases intraluminal baseline impedance levels. Am J Gastroenterol 2011;106:2093-2097.

38 Martinucci I, De Bortoli N, Savarino E, et al: Esophageal baseline impedance levels in patients with pathophysiological characteristics of functional heartburn. Neurogastroenterol Motil 2014;26:546-555.

39 Kandulski A, Weigt J, Caro C, Jechorek D, Wex T, Malfertheiner P: Esophageal intraluminal baseline impedance differentiates gastroesophageal reflux disease from functional heartburn. Clin Gastroenterol Hepatol 2015;13:1075-1081. 